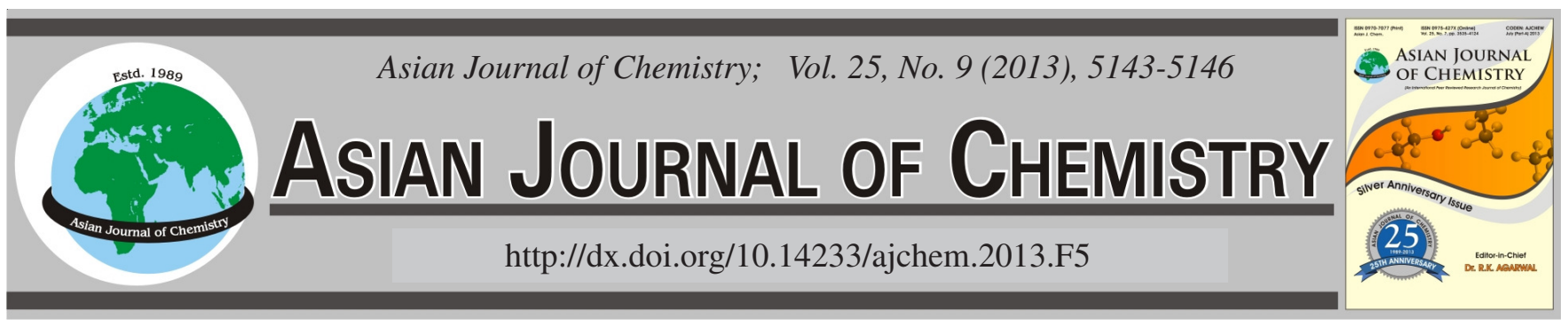

\title{
Miscibility, Thermal, Morphological and Mechanical Behaviour of Polycarbonate/poly(trimethylene terephthalate)blends with Poly(butylene adipate-co-terephthalate) as a Compatibilizer $\dagger$
}

\author{
S.B. KIM ${ }^{1}$, H.R. KIM ${ }^{1}$ and B.U. NAM ${ }^{1, *}$
}

Department of Applied Chemical Engineering, Korea University of Technology and Education, Cheonan, Republic of Korea

*Corresponding author: Fax: +82 42 5601224; Tel: +82 41 5601345; E-mail: bunam@kut.ac.kr

The thermal, mechanical and morphological behaviour of polycarbonate (PC), poly(trimethylene terephthalate) (PTT) and poly(butylene adipate-co-terephthalate) (PBAT) polymer blends were investigated. Several blends were prepared by a melt mixing process using a twinscrew extruder. Dynamic mechanical analysis and field emission scanning electron microscopy showed that PC/PTT binary blends provide a compatible system. In the PC/PTT/PBAT ternary blends, poly(butylene adipate-co-terephthalate) led to improved compatibility. In particular, the PC20PTT80BA composition was a miscible system. The thermal degradation and mechanical properties were characterized by thermogravimetric analysis and a notched-izod impact test, respectively. The results showed that that poly(butylene adipate-co-terephthalate) plays an important role as a compatibilizer in PC/PTT/PBAT blends.

Key Words: Polycarbonate, Poly(trimethylene terephthalate), Poly(butylene adipate-co-terephthalate), Compatibilizer.

ᄂ - - - - - - - - - - - - - - - - - - - - - - - - - -

\section{INTRODUCTION}

Poly(trimethylene terephthalate) (PTT), a bio-based polymer derived from biomass resource, is a new type of polyester. The two monomer units used to produce this polymer are 1,3-propane diol (PDO) and terephthalic acid or dimethyl terephthalate. In recent years, companies, such as DuPont, have reported the biological production of 1,3-propanediol using renewable feedstock, such as corn. Poly(trimethylene terephthalate) has good mechanical strength and stiffness, low warpage and good dimensional stability.

Polycarbonate (PC), a type of engineering plastic, has good mechanical properties but is difficult to process owing to its high melt viscosity and low chemical resistance. Many researchers have attempted to prepare polycarbonate blends with other polymers. This route is considered an effective way of tailoring the specific performance properties of the desired polymers. In particular, polycarbonate blends with various polyesters, such as poly(ethylene terephthalate) (PET) ${ }^{1-3}$, poly(butylene terephthalate) $(\mathrm{PBT})^{4-7}$, poly(trimethyl terephthalate) $(\mathrm{PTT})^{8-13}$ and polylactic acid (PLA) ${ }^{14,15}$, have attracted increasing attention because $\mathrm{PC} /$ polyester blends can react by transesterification in the molten state. The random copolymer formed by transesterification leads to miscible PTT/PC blends ${ }^{8,11}$. An annealing method is frequently performed for high transesterification rates.
On the other hand, the processing cost and energy consumption are increased by annealing, which involves an additional step under high temperatures. To address these problems, poly(butylenes adipate-co-terephthalate)(PBAT) was introduced as a compatibilizer to PTT/PC blends. Poly(butylenes adipate-co-terephthalate) is a representative aliphatic-aromatic copolyester that is prepared by the melt polycondensation of 1,4-butanediol, adipic acid and terephthalic acid. The material has improved properties including softness, which is on par with that of low density polyethylene (LDPE) and strong potential for use as a biodegradable polymer.

The PC/PTT/PBAT blends were prepared using a twinscrew extruder. The miscibility and thermal and mechanical properties were measured by field emission-scanning electron microscopy (FE-SEM), dynamic mechanical analysis (DMA), thermogravimetric analysis (TGA) and a notched-Izod Impact Test. The PC/PTT/PBAT blends showed a partially miscible system, as well as enhanced mechanical and thermal properties in some compositions.

\section{EXPERIMENTAL}

Poly(trimethylene terephthalate) (PTT, SORONA, 3301 $\mathrm{NC}, \mathrm{d}=1.4, \mathrm{MI}=30 \mathrm{~g} / 10 \mathrm{~min}$ at $300^{\circ} \mathrm{C}, 1.2 \mathrm{~kg}$ ) was purchased from Dupont, USA. Polycarbonate was obtained from Samyang Co., Korea. The polycarbonate has a melt flow rate of $50 \mathrm{~g} / 10$ 
$\min \left(\right.$ at $300{ }^{\circ} \mathrm{C}, 1.2 \mathrm{~kg}$ ). Poly(butylene adipate-co-terephthalate) (PBAT, $\mathrm{T}_{\mathrm{g}}=-30{ }^{\circ} \mathrm{C}, \mathrm{T}_{\mathrm{m}}=110-120^{\circ} \mathrm{C}$, Ecoflex BX7011) was supplied by BASF. All materials were dried at $60{ }^{\circ} \mathrm{C}$ for $12 \mathrm{~h}$ prior to melt blending to minimize any hydrolysis degradation.

Blends and sample preparation: All the blends were mixed thoroughly prior to extrusion. Melt blending of the dried poly(trimethylene terephthalate), polycarbonate and poly(butylenes adipate-co-terephthalate) was carried out using a twin-screw extruder (Bautek, Korea, L/D = 42, D = 19Ø). The barrel temperature ranged from $220^{\circ} \mathrm{C}$ to $270{ }^{\circ} \mathrm{C}$ and the screw speed was $150 \mathrm{rpm}$. The polymers were mixed at the required weight ratios: (PC/PTT) 100/0, 80/20, 65/35, 50/50, 35/65, $20 / 80$ and 0/100. Poly(butylenes adipate-co-terephthalate) was introduced at $5 \mathrm{phr}$ as a compatibilizer. The samples are denoted PC80PTT20BA, PC20PTT80BA, etc. The samples for FE-SEM, DMA and an evaluation of mechanical properties were injection molded using injection molding machine. The barrel, nozzle and mold temperature was 300,280 and $50{ }^{\circ} \mathrm{C}$, respectively. The injection speed and holding pressure was 10 $\mathrm{mm} / \mathrm{s}$ and $140 \mathrm{MPa}$ for $30 \mathrm{~s}$, respectively.

DMA (DMA8000, Perkin-Elmer) was carried out at temperatures ranging from $0{ }^{\circ} \mathrm{C}$ to $180{ }^{\circ} \mathrm{C}$ at a heating rate of $2{ }^{\circ} \mathrm{C} / \mathrm{min}$ with a frequency of $1 \mathrm{~Hz}$. To examine the thermal stability of the blends, TGA (TGA4000, Perkin-Elmer) was conducted from $30{ }^{\circ} \mathrm{C}$ to $800^{\circ} \mathrm{C}$ at a heating rate of $20 \mathrm{~K} / \mathrm{min}$. The morphology of the blends was analyzed by FE-SEM (JSM7500F, JEOL Led., Japan). A notched-izod impact strength test was performed using a SJTm-131 (Sejin, Korea) according to the ASTM D256.

\section{RESULTS AND DISCUSSION}

DMA is the most widely used approach in thermal analyses for measuring the mechanical properties at various temperatures and can identify the glass transition and how various system modifications affect the glass transition temperature $\left(\mathrm{T}_{\mathrm{g}}\right)$. Miscible binary polymer blends exhibit a single $\mathrm{T}_{\mathrm{g}}$ between the $\mathrm{T}_{\mathrm{gs}}$ of neat components. The Tgs are well separated if the polymers are immiscible ${ }^{16}$.

Fig. 1 shows the temperature dependence of the $\tan \delta$ in the PC/PTT blends. The glass transition temperatures of polycarbonate and poly(trimethylene terephthalate) were $150^{\circ} \mathrm{C}$ and $71{ }^{\circ} \mathrm{C}$, respectively. In the PC/PTT binary blends, there was a slight shift in $\mathrm{T}_{\mathrm{g}}$ with the value falling between those of the pure polymers depending on the composition. The binary blends of polycarbonate and poly(trimethylene terephthalate) appear to form a partially compatible blend system. Fig. 2 presents the glass transition temperatures of PC/PTT/PBAT ternary blends. After introducing poly(butylenes adipate-co-terephthalate) as a compatibilizer, the two separated $\mathrm{T}_{\mathrm{g}}$ peaks approached each other and became similar with increasing poly(trimethylene terephthalate) content. A single $\mathrm{T}_{\mathrm{g}}$ was observed in the PC20PTT80BA blends at $88^{\circ} \mathrm{C}$. This phenomenon can be explained in terms of the solubility parameter. The solubility parameter of polycarbonate, poly(trimethylene terephthalate) and poly(butylenes adipate-co-terephthalate) is $22.99\left(\mathrm{~J} / \mathrm{cm}^{3}\right)^{1 / 2}, 24.60\left(\mathrm{~J} / \mathrm{cm}^{3}\right)^{1 / 2}$ and $22.69\left(\mathrm{~J} / \mathrm{cm}^{3}\right)^{1 / 2}$, respectively, which was calculated based on the Hildebrand and Scott equation using Fedor's method ${ }^{16}$. The solubility parameter of poly(butylenes adipate-co-terephthalate) is closer to that of polycarbonate than poly(trimethylene terephthalate). As a result, poly(butylenes adipate-co-terephthalate) is dispersed into the polycarbonate phase. Fig. 3 shows the expected morphology of polycarbonate, poly(trimethylene terephthalate) and poly(butylenes adipate-co-terephthalate). The morphological development of the blends was affected by the solubility parameters and relative viscosities. The compatibility was improved to some extent when poly(trimethylene terephthalate) and poly(butylenes adipate-co-terephthalate) form domains in the polycarbonate-rich blends because the $\mathrm{T}_{\mathrm{g}}$ of polycarbonate was decreased by the plasticizing effect of poly(butylenes adipate-co-terephthalate $)^{17}$. On the other hand, the compatibility was improved significantly when the poly(butylenes adipate-co-terephthalate) domains were located inside or on the surface of the polycarbonate domains in the poly(trimethylene terephthalate)-rich blend ${ }^{18,19}$. The domain was dispersed finely and the size became smaller due to the rheological effect of low viscosity of polycarbonate compared to the matrix poly(trimethylene terephthalate). This is consistent with the DMA result shown in Fig. 2. This suggests that a partially compatible system of PC/PTT blends is changed to a miscible system due to the effects of the compatibilizer, poly(butylenes adipate-coterephthalate).

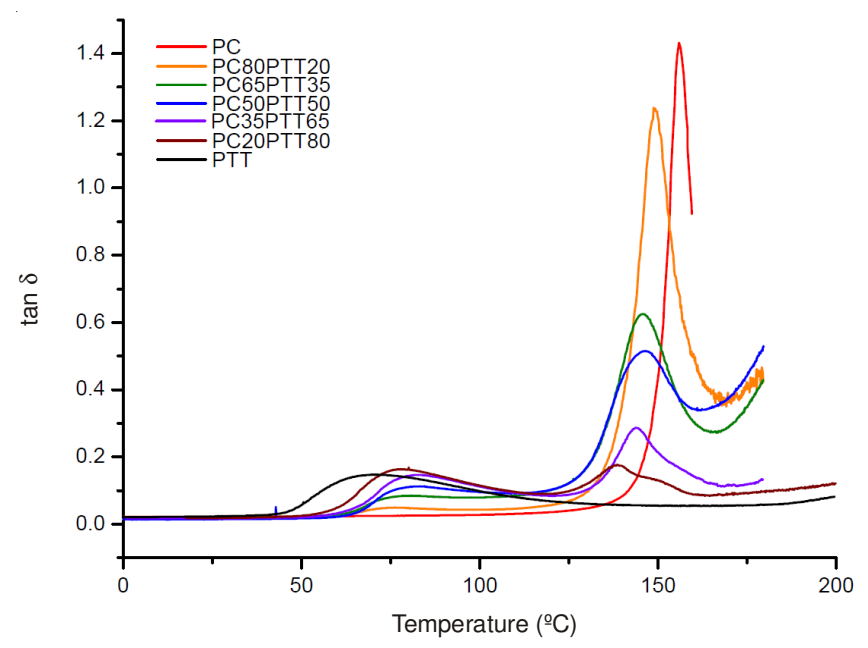

Fig. 1. Temperature dependence of $\tan \delta$ for the PC/PTT binary blends

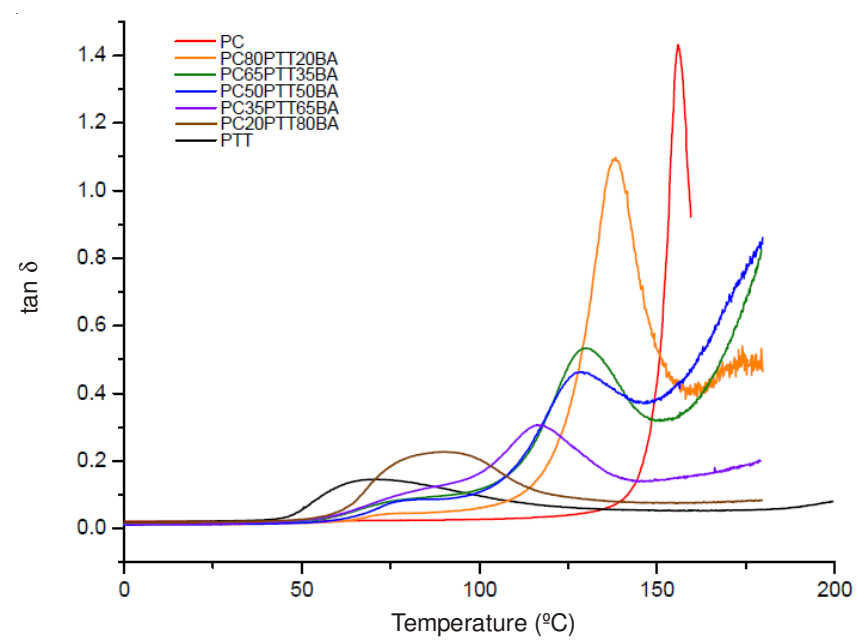

Fig. 2. Temperature dependence of $\tan \delta$ for the PC/PTT/PBAT ternary blends 

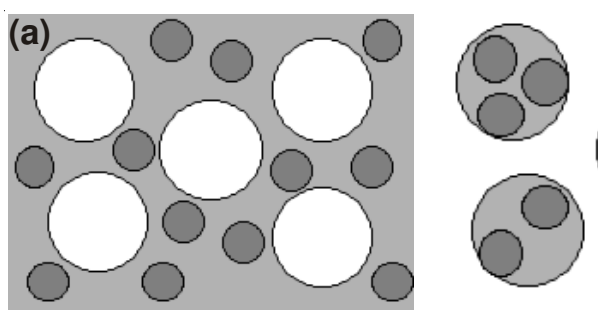

(b)

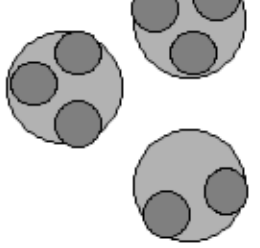

Fig. 3. Expected images of PC/PTT/PBAT blends morphology a) PTT domains in PC matrix, b) PC domains n PTT matrix (white phase = PTT, light gray $=$ PC, dark gray $=$ PBAT)

The morphological development and stability of multiphase polymer melts are complex functions of the interfacial characteristics, blend composition, rheological properties and shear conditions. Fig. 4a and c) show FE-SEM images of the PC80PTT20 and PC20PTT80 blends. Compared to the PC80PTT20 blends, polycarbonate develops smaller domains than poly(trimethylene terephthalate) in the PC20PTT80 blends. The difference between the dispersed particle sizes of the polycarbonate and poly(trimethylene terephthalate) phases for a given dispersed-phase concentration can be explained by considering the relative difference in their viscosities in the blends. The less viscous component forms finely dispersed particles in the more viscous matrix (PTT) because of the comparatively restricted diffusion effects on the coalescence of particles and the increased shear stress resulting from the more viscous matrix phase ${ }^{12}$. The domain sizes in the morphology of the PC80PTT20 and PC80PTT20BA blends were decreased by introducing the poly(butylenes adipate-coterephthalate) compatibilizer.

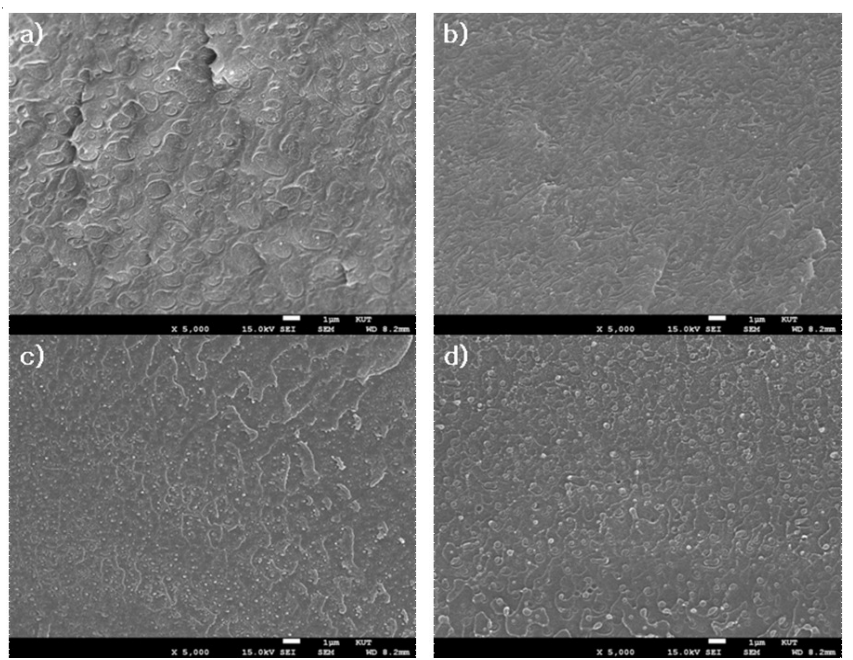

Fig. 4. FE-SEM images of cryo-fractured surfaces of PC/PTT and PC/PTT/ PBAT blends a) PC80PTT20, b) PC80PTT20BA, c) PC20PTT80, d) PC20PTT80BA(X5,000, scale bar = 1um)

Fig. 5 shows the effect of the blend ratio on the thermograms of PC/PTT and PC/PTT/PBAT blends. Poly(trimethylene terephthalate) is more susceptible to degradation, whereas polycarbonate shows the maximum thermal stability. Polycarbonate forms a matrix and poly(trimethylene terephthalate) is the dispersed phase in the PC80PTT20 and PC80PTT20BA blends. Increasing the initial decomposition temperature of poly(trimethylene terephthalate) in the blends depends on its phase morphology. This suggests that the thermal degradation of poly(trimethylene terephthalate) is restricted because the polycarbonate matrix offers protection to the dispersed poly(trimethylene terephthalate) domains ${ }^{12}$. On the other hand, there are no differences between the PC50PTT50 and PC50PTT50BA blends. The thermal stability increases with increasing amount of polycarbonate in the blends, but poly(butylenes adipate-co-terephthalate) does not affect the thermal stability. The thermal stability of the blends depends on the phase and morphology ${ }^{12}$.

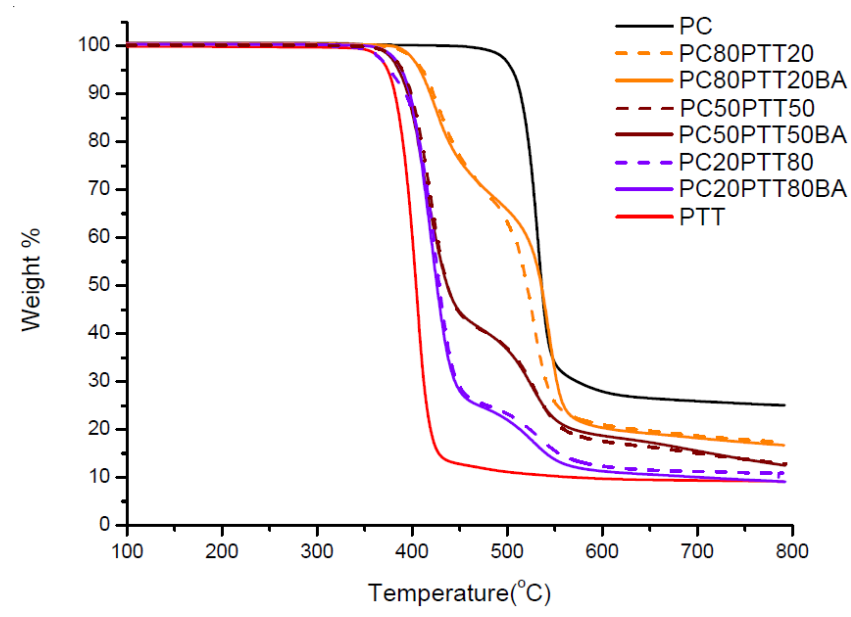

Fig. 5. Effect of the blend ratio on the thermograms of the PC/PTT and $\mathrm{PC} / \mathrm{PTT} / \mathrm{PBAT}$ blends

As shown in Fig. 6, the notched-izod impact strength of the blends, where poly(trimethylene terephthalate) is the major component, is not affected by poly(butylenes adipateco-terephthalate). On the other hand, the impact strength is improved by poly(butylenes adipate-co-terephthalate) in the blends where polycarbonate is the major component. Poly(butylenes adipate-co-terephthalate) improves the compatibility and polycarbonate retains its original impact strength as the domain sizes of poly(trimethylene terephthalate) dispersed in the polycarbonate matrix become smaller. This is consistent with the results from FE-SEM.

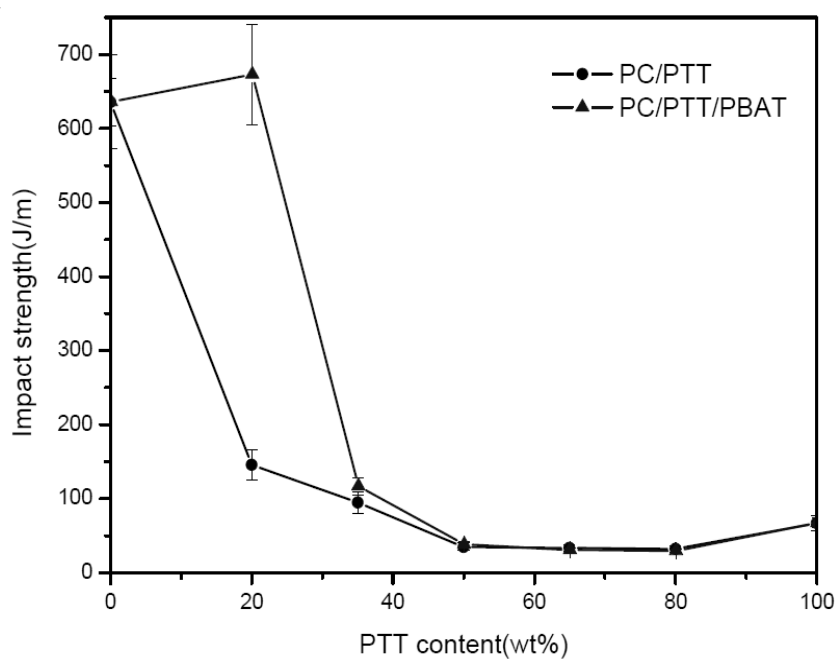

Fig. 6. Effect of the blend ratio on the Notched izod-impact strength of the $\mathrm{PC} / \mathrm{PTT}$ and PC/PTT/PBAT blends 


\section{Conclusion}

The effects of a compatibilizer on the PC/PTT blends were examined by DMA, FE-SEM, TGA and a notched-Izod impact test. The blends were prepared by melt mixing and subsequent injection molding. DMA revealed improved compatibility on the overall composition. In particular, poly(butylenes adipateco-terephthalate) rendered the PC80PTT20BA blends a miscible system. FE-SEM revealed a uniformly dispersed morphology. The thermal stability of the blends was dependent on the phase morphology. The polycarbonate matrix had a protective effect on the dispersed poly(trimethylene terephthalate) domains and improved the thermal stability of poly(trimethylene terephthalate). The decrease in the poly(trimethylene terephthalate) domain size by poly(butylenes adipate-coterephthalate) increased the impact strength of the PC80PTT20BA blends.

\section{ACKNOWLEDGEMENTS}

This study was supported by the Ministry of Education, Science Technology (MEST) and National Research Foundation of Korea (NRF) through the Human Resource Training Project for Regional Innovation and by a grant from the cooperative R \& D Program funded by the Korea Research Council Industrial Science and Technology.

\section{REFERENCES}

1. Y.M. Lee and D.W. Kang, J. Korean Ind. Eng. Chem., 5, 54 (1993).

2. Y. Kang and J.N. Hay, Polymer, 43, 1805 (2002).

3. Z. Zhang, Y. Xie and D. Ma, Eur. Polym. J., 37, 1961 (2001)

4. E.M.S. Sanchez, Polym. Test., 26, 378 (2007).

5. J.M.R.C.A. Santos and J.T. Guthrie, J. Mater. Chem., 16, 237 (2005).

6. M.Y. Lyu, D.H. Chol, Y.H. Kim and C.W. Nah, Polymer (Korea), 34, 237 (2010)

7. C.W. Nah, M.Y. Huh, D.H. Chol, J.H. Kook, I.R. Hwang, K.U. Jeong and C.K. Hong, Polymer (Korea), 31, 399 (2007).

8. I. Aravind, K.J. Eichhorn, H. Komber, D. Jehnichen, N.E. Zafeiropoulos, K.H. Ahn, Y. Grohens, M. Stamm and S. Thomas, J. Phys. Chem. B, 113, 1569 (2009).

9. M.L. Xue, Y.L. Yu, J. Sheng, H.H. Chuah and C.H. Geng, J. Macromol. Sci. Part B: Phys., 44, 317 (2005).

10. M.L. Xue, Y.L. Yu, J. Sheng, H.H. Chuah and C.H. Geng, J. Macromol. Sci. Part B: Phys., 44, 331 (2005).

11. A. Yavari, A. Asadinezhad, S.H. Jafari, H.A. Khonakdar, F. Bohme and Hassler, Eur. Polym. J., 41, 2880 (2005).

12. I. Aravind, A. Boumod, Y. Grohens and S. Thomas, Ind. Eng. Chem. Res., 49, 3873 (2010).

13. I. Gonza'lez, J.I. Eguiaza'bal and J. Nazabal, J. Appl. Polym. Sci., 108, 3828 (2008).

14. T. Kanzawa and K. Tokumitsu, J. Appl. Polym. Sci., 121, 2908 (2011).

15. K. Hashima, S. Nishitsuji and T. Inoue, Polymer, 51, 3934 (2010).

16. L.H. Sperling, Introduction to Physical Polymer Science, Chap. 3, Wiley Interscience, p. 71 (2005).

17. M.O. Jang, S.B. Kim and B.U. Nam, Polym. Bull., 68, 287 (2012).

18. L.H. Sperling, Introduction to Physical Polymer Science, Chap. 4, Wiley Interscience, p. 145 (2005).

19. Y. Li and H. Shimizu, Appl. Mater. Int., 1, 1650 (2009). 